Paidéia, 2004, 14(29), 277-286

\title{
A RELAÇÃO ENTRE O ENVOLVIMENTO PATERNO E O DESEMPENHO ACADÊMICO DOS FILHOS ${ }^{1}$
}

\author{
Fabiana $\mathrm{Cia}^{2}$ \\ Sabrina Mazo D’Affonseca \\ Elizabeth Joan Barham \\ Universidade Federal de São Carlos
}

Resumo: O objetivo deste trabalho foi o de estudar o impacto da qualidade do relacionamento entre pai e filho sobre o desempenho acadêmico de crianças escolares. Participaram deste estudo 58 pais e seus filhos da 5a e 6a séries. Os pais preencheram o questionário "Qualidade da interação familiar na visão paterna” e os filhos preencheram o questionário "Interação pai-filho". Para investigar como o envolvimento dos pais afetou o desempenho acadêmico dos seus filhos, as crianças foram avaliadas com o "Teste de Desempenho Escolar". Observou-se que, quanto maior a freqüência de comunicações entre pai e filho e quanto maior o envolvimento dos pais nas atividades escolares, culturais e de lazer do filho, melhor o desempenho acadêmico das crianças. Tais resultados demonstram a importância do pai para o desempenho acadêmico dos filhos e apontam para a necessidade de educar os homens para conhecerem as muitas ações que podem melhorar seu desempenho enquanto pais.

Palavras-chave: envolvimento paterno; relacionamento pai-filho; desempenho acadêmico; papel do pai.

\section{THE RELATIONSHIP BETWEEN FATHER INVOLVEMENT AND CHILDREN'S ACADEMIC PERFORMANCE}

\begin{abstract}
The aim of this paper was to study the impact of the quality of the father-child relationship on children's academic performance. A total of 58 fathers and their children (in the fifth and sixth grades) participated in this study. The fathers completed a questionnaire, "Quality of family interaction - fathers' perspective" and the children completed a questionnaire "Father-child interaction". To investigate how the fathers' involvement affected their children's academic performance, the children were evaluated using the School Performance Test. The results indicate that, the higher the frequency of father-child communication and the greater the fathers' involvement in the children's school, cultural and leisure activities, the higher the children's academic performance. These results indicate the importance of fathers' involvement, to maximize children's academic performance, and the necessity of educating men with respect to the ways in which they can improve their parental performance.
\end{abstract}

Key-words: paternal involvement; father-child relationship; academic performance; father role.

Sabe-se que uma interação inadequada entre pai e filho é considerada um fator de risco para o desenvolvimento infantil (Fagan \& Iglesias, 1999; Feldman \& Klein, 2003). Estudos que enfatizam as implicações para o desenvolvimento infantil decorrentes da ausência paterna, normalmente priorizam duas variáveis: a ausência decorrente do divórcio e a ausência decorrente das poucas interações entre pai e filho, mesmo morando na mesma casa (Lamb, 1997; Black, Dubowitz \& Starr, 1999; Marshall, English \& Stewart, 2001). A presente pesquisa investiga a importância da qualidade das interações entre pais e filhos para o desempenho acadêmico das crianças, considerando pais que moram com os filhos.

Muitos estudos mostram que o envolvimento do pai afeta a dedicação dos seus filhos aos estudos,

\footnotetext{
${ }^{1}$ Artigo recebido para publicação em 01/07/2004; aceito em 22/11/2004

2 Endereço para correspondência: Fabiana Cia, Rua das Poncianas, 837, Jardim São Paulo, Americana, SP, 13465-000, E-mail: fabianacia@hotmail.com
} 


\section{Fabiana Cia}

com impactos no seu desempenho acadêmico. Pesquisas investigando a associação entre cuidados oferecidos pelo pai e o aproveitamento acadêmico da criança revelam que aquelas que contam com o acompanhamento do seu pai em relação ao seu desempenho acadêmico (pai com interesse nos estudos do filho, ajuda-o nas tarefas de casa e o apóia quando apresenta baixo desempenho acadêmico) têm mais motivação para ir à escola, estudam com maior freqüência e mostram melhor aproveitamento acadêmico (Vizzotto, 1988). Além da questão do desempenho em si, Engle e Breaux (1998) afirmaram que o envolvimento do pai contribui para melhor desenvolvimento intelectual do filho e, por conseqüência, para melhor adaptação e desempenho deste na escola. Coley (1998), em um estudo com crianças de $3^{\underline{a}}$ e $4^{\text {a }}$ séries, verificou que as que relataram ter maior grau de envolvimento com o pai tiveram menos problemas de comportamento em sala de aula e melhor desempenho acadêmico do que as de pouco envolvimento com o pai.

Nesse mesmo sentido, uma pesquisa realizada por Biller e Kimpton (1997) apontou que as crianças em idade escolar, de ambos os sexos, com interações mais freqüentes com o pai, mostraram maiores habilidades motoras e para tarefas manipulativas. Além disso, as que viviam com o pai biológico apresentaram maior desenvolvimento intelectual e funcionamento cognitivo do que as que viviam com outra figura masculina ou em famílias monoparentais, sendo que o baixo nível socioeconômico aumentou estes efeitos adversos. Esses autores concluíram que a ausência paterna para crianças em idade escolar é um fator de risco para: desenvolvimento de problemas psicológicos, freqüência de interações sociais e competência social e intelectual.

Amato e Gilbreth (1999) fizeram uma metaanálise de 63 estudos para investigar o impacto de diferentes aspectos do relacionamento com o pai sobre o bem-estar das crianças. Eles concluíram que crianças com menos problemas de comportamento e melhor desempenho acadêmico tinham pais (homens) que ofereciam mais suporte e apoio emocional, quando comparadas com as de pouco contato com o pai ou de pai autoritário. O estudo também evidenciou que a qualidade do relacionamento, e não apenas a quantidade de interação entre pais e filhos, era o preditor mais importante de bons resultados no desenvolvimento infantil.

Além de estudos com crianças em idade escolar, outras pesquisas mostram que o envolvimento do pai também afeta o desempenho acadêmico dos seus filhos adolescentes. Pelegrina, García-Linares e Casanova (2003) fizeram uma pesquisa com 370 adolescentes e seus pais. Como principal resultado, verificaram que o envolvimento com o pai estava positivamente correlacionado ao desempenho acadêmico (na percepção dos adolescentes e da professora) e à motivação dos filhos para os estudos.

Numa pesquisa longitudinal, Flouri e Buchanan (2003) também investigaram a influência do pai no desempenho acadêmico e nas habilidades gerais do filho, focalizando a interação paterna com a criança. Os pesquisadores acompanharam 8841 famílias residindo na Inglaterra, provenientes de classes socioeconômicas variadas, observando a associação entre a interação pai-filho e o desenvolvimento dos filhos em diferentes idades, até a fase adulta. Os resultados indicaram que maior envolvimento do pai, quando o filho era criança, relacionava-se com melhor desempenho acadêmico e maior repertório de habilidades gerais do filho, quando adolescente, além de influir no sucesso profissional dos filhos, quando adultos.

Fica, pois,evidente o papel fundamental dos pais no desempenho acadêmico dos filhos, ajudando-os na organização do seu tempo de estudo e dando incentivo a eles (Vallejo-Nágera, 1997).

\section{A necessidade de estudos brasileiros sobre o envolvimento paterno e o desempenho acadê- mico dos filhos}

Os estudos citados foram conduzidos em contextos culturais diferentes do brasileiro, o que não permite saber como é a qualidade do relacionamento entre pai e filho no Brasil. Além disso, o papel do pai se encontra em uma fase de transição, sendo freqüente as famílias em que ambos trabalham fora, o que tem levado à redefinição do papel paterno, com algumas das responsabilidades familiares sendo repassadas aos homens, principalmente em relação aos cuidados com os filhos (Jablonski, 1999). Os impactos dessas mudanças para o desenvolvimento infantil 
somente poderão ser conhecidos a partir de estudos que avaliem a interação pai e filho e o desenvolvimento infantil (Dessen \& Lewis, 1998; Diniz, 1999; Bertolini, 2002). Estudos dessa natureza ajudariam também na identificação de fatores de risco, o que é importante, considerando-se o contexto da educação pública brasileira, em que há um número cada vez maior de alunos com baixo desempenho acadêmico, erroneamente rotulados como deficientes e encaminhados para classes ou escolas especiais. Quando isto não acontece, estes alunos engrossam as estatísticas sobre o número de repetentes e de evasão escolar, ou seja, de fracasso escolar ${ }^{3}$.

Sendo assim, os objetivos desta pesquisa foram:

1. Verificar a freqüência e o tipo de envolvimento da figura paterna com os filhos;

2. Avaliar o desempenho acadêmico dos filhos e

3. Avaliar o impacto da qualidade do relacionamento entre pai e filho sobre o desempenho acadêmico de crianças escolares.

\section{Método}

\section{Participantes}

Participaram deste estudo 58 pais, com média de idade de 39 anos, variando entre 31 e 61 anos. Em relação ao grau de escolaridade, 41,4\% possuíam 2o grau completo, $37,9 \% 1^{\circ}$ grau completo e $20,7 \% 1^{\circ}$ grau incompleto, sendo que em média, os pais tinham 8,4 anos de escolaridade. No que diz respeito aos recursos financeiros, 93,1\% dos pais apresentavam renda familiar entre $\mathrm{R} \$ 500,00$ a $\mathrm{R} \$ 1000,00$ e $6,9 \%$ de $\mathrm{R} \$ 250,00$ a $\mathrm{R} \$ 500,00$. Além dos pais, também participaram 58 crianças, com idade média de 12 anos, variando entre 10 e 14 anos, sendo 30 do sexo feminino e 28 do sexo masculino, e a metade de cada grupo estava na $5^{\mathrm{a}}$ série e metade na $6^{\mathrm{a}}$ série.

\section{Local da coleta de dados}

A distribuição do questionário aos pais e a coleta de dados junto às crianças ocorreram em uma escola localizada em uma cidade de médio porte no interior do estado de São Paulo. Foi disponibilizada uma sala isenta de ruídos para as atividades relacionadas a este estudo. Essa escola é considerada particular porque é mantida pelas indústrias (rede de ensino SESI), mas os alunos não pagam para estudar. Em primeiro lugar, as vagas são oferecidas para filhos de pais que trabalham nas indústrias conveniadas com o SESI; as vagas excedentes são abertas para crianças da comunidade.

Uma das metas prioritárias da rede de ensino SESI é a de manter um relacionamento sistemático com as famílias dos alunos, criando uma parceria paisescola que possa trazer melhoria na qualidade de vida e no desempenho escolar do aluno. As reuniões entre os professores e os pais são realizadas ou no início da manhã (às 7:00 horas) ou no final da tarde (após 18:00 horas), permitindo que todos possam comparecer, mesmo quando trabalham no período noturno.

\section{Medidas avaliativas}

Questionário para os pais - Os pais preencheram o instrumento "Qualidade da interação familiar na visão paterna”, construído com base em instrumentos já existentes (Cohen \& Williamson, 1988; Sorano \& Barham, 1999; Bolsoni-Silva, 2000; Faria \& Barham, 2002) e dividido em três partes:

1. Identificação: dados sociodemográficos.

2. Habilidades sociais educativas dos pais para com os filhos: escala de comunicações (verbais e não verbais) entre pai e filho, segundo o pai, contendo 22 itens (ver itens Tabela 1), com a pontuação variando entre 0 (nunca) a 365 (uma vez por dia).

3. Participação dos pais nas atividades escolares, culturais e de lazer dos filhos: escala da participação do pai nas atividades escolares, culturais e de lazer dos filhos, contendo 15 itens (ver itens Tabela 3), com pontuação variando de 0 (nunca) a 365 (todos os dias).

Questionário para as crianças - As crianças preencheram o instrumento "Interação pai-filho", questionário que contém uma escala de comunicações (verbais e não verbais) entre pai e filho, segundo o filho, com nove itens (ver itens Tabela 2), e pontuação vari-

\footnotetext{
${ }^{3}$ Dados da secretaria municipal de educação da cidade em que a pesquisa foi realizada revelaram que 45,9\% dos alunos que freqüentam salas de reforço são tidos como crianças que apresentam fracasso escolar (Mendes, 2002).
} 


\section{Fabiana Cia}

ando entre 0 (nunca) a 365 (uma vez por dia).

Teste de Desempenho Escolar-TDE - Para obter um índice do desempenho escolar das crianças, foi utilizado o "Teste de Desempenho Escolar" (TDE) de Stein (1994), um instrumento com propriedades psicométricas adequadas quanto a sua confiabilidade interna, avalia as capacidades fundamentais para o desempenho escolar, é composto de três sub-testes- escrita, a aritmética e leitura-tendo sido concebido para escolares de $1^{\underline{a}}$ a $6^{\underline{a}}$ séries do Ensino Fundamental.

\section{Procedimento de coleta de dados}

O primeiro contato com os pais se deu por meio de uma reunião de pais, em que a pesquisadora explicou os objetivos da pesquisa, como seria sua participação e o teste que aplicado aos filhos. Em seguida, foi entregue o instrumento "Qualidade da interação familiar na visão paterna”, explicado cada item aos pais que quiseram participar e aceitaram o mesmo para seu filho. Eles também receberam os termos de consentimento livre e esclarecido.

As crianças cujos pais entregaram o instrumento preenchido e autorizaram sua participação completaram, primeiramente, o questionário "Interação paifilho”, em que a pesquisadora falava em voz alta cada item e os alunos colocavam a freqüência que condizia com sua realidade. A aplicação durou em média de 20 minutos. Em seguida, foi aplicado o TDE (aplicação individual), que levou cerca de 60 minutos.

\section{Procedimento de análise de dados}

Os dados quantitativos, obtidos com os questionários "Qualidade da interação familiar na visão paterna" e "Interação pai-filho" foram analisados estatisticamente segundo medidas de tendência cen- tral e dispersão. Para os itens que compõem escalas, verificou-se a consistência interna (alpha de Cronbach) e as pontuações dos dados foram feitas com base no manual deste instrumento.

Para investigar a relação entre o desempenho acadêmico das crianças e o tipo e grau de envolvimento de seus respectivos pais, foi utilizado o teste de correlação de Pearson - aplicativo SPSS 10.0.

\section{Resultados e Discussão}

Os resultados mostram os aspectos do relacionamento entre pai-filho avaliados e a influência destes aspectos sobre o desempenho acadêmico dos filhos e serão apresentados em três partes: (a) comunicações entre pais e filhos; (b) participação dos pais nas atividades escolares, culturais e de lazer dos filhos e (c) desempenho acadêmico das crianças e relacionamento entre pai e filho. Verificou-se, através de testes estatísticos, que não houve diferenças significativas entre envolvimento paterno e desempenho escolar e as variáveis sociodemográficas dos participantes (idade, anos de escolaridade do pai, idade e sexo da criança, renda familiar).

\section{Comunicações entre pais e filhos}

A literatura da área demonstra correlações importantes entre habilidades sócio- educativas dos pais e o desenvolvimento global satisfatório da criança (Lamb, 1997; Lewis \& Dessen, 1999; Feldman \& Klein, 2003). Para tanto, investigaram-se os tipos e as freqüências de comunicações (verbais e não verbais) entre pai e filho, segundo o pai, e de comunicações (verbais e não verbais) entre pai e filho, segundo o filho. A Tabela 1 apresenta a freqüência de comunicações entre pai e filho, segundo o pai. 
Tabela 1: Escala de comunicações entre pai e filho, segundo o pai.

\begin{tabular}{|c|c|c|}
\hline Item & $\begin{array}{c}\text { Frequência } \\
\text { média } \\
\text { (dias/ano) }\end{array}$ & D. P. \\
\hline \multicolumn{3}{|l|}{ Você. } \\
\hline Dá carinho a seu filho? & 269,3 & 136,8 \\
\hline Expressa sentimentos positivos em relação às atitudes de seu filho? & 269,1 & 136,5 \\
\hline Impōe limites a seu filho? & 264,2 & 138,7 \\
\hline Mantém diálogo com seu filho? & 255,4 & 140,0 \\
\hline Oferece ajuda ao seu filho, quando precisa? & 254,1 & 141,5 \\
\hline Pergunta para seu filho sobre aspectos do dia a dia? & 247,3 & 145,3 \\
\hline Expressa suas opiniões a seu filho? & 239,0 & 138,2 \\
\hline Elogia seu filho? & 224,6 & 145,4 \\
\hline Pergunta para seu filho sobre o que aconteceu na escola? & 220,5 & 150,9 \\
\hline Quando você promete algo a seu filho, você cumpre a promessa? & 212,8 & 161,6 \\
\hline Expressa seus sentimentos negativos às atitudes de seu filho? & 167,2 & 157,3 \\
\hline Pergunta para seu filho sobre seus amigos? & 161,9 & 145,2 \\
\hline \multicolumn{3}{|l|}{ Seu filho... } \\
\hline Procura conversar com você? & 237,2 & 141,7 \\
\hline Dá carinho (abraços, beijos)? & 236,3 & 158,2 \\
\hline Conta as coisas boas e ruins ocorridas com ele em relação aos amigos? & 197,6 & 149,5 \\
\hline Conta as coisas boas ou ruins ocorridas com ele em relação à escola? & 195,4 & 150,3 \\
\hline Solicita que você faça algo por ele? & 178,6 & 147,8 \\
\hline Faz perguntas referentes ao seu dia a dia? & 177,6 & 154,4 \\
\hline Faz elogios a você? & 146,7 & 149,7 \\
\hline Pede para que você o ajude em alguma atividade (acadêmica ou não)? & 135,2 & 131,8 \\
\hline Expressa desejos e preferências, dando razão para suas ações e posições? & 129,6 & 145,4 \\
\hline Desafia suas regras (desobediência)? & 74,4 & 109,7 \\
\hline
\end{tabular}

Pela Tabela 1, observa-se que há uma reciprocidade no relacionamento entre estes, também se comunicavam através das formas avaliadas neste estudo, quase todos os dias.

\section{Comunicações pai e filho, segundo o filho}

A Tabela 2 apresenta a freqüência de comunicações (verbais e não verbais) entre pai e filho, segundo o filho.

Tabela 2: Escala de comunicações entre pai e filho, segundo o filho

\begin{tabular}{|c|c|c|}
\hline Item & $\begin{array}{c}\text { Frequiência } \\
\text { média } \\
\text { (dias/ano) }\end{array}$ & D. P. \\
\hline \multicolumn{3}{|l|}{ Seu pai... } \\
\hline Faz perguntas referentes ao seu dia a dia & 286,9 & 130,4 \\
\hline Dá carinho & 281,9 & 121,9 \\
\hline Faz elogios a você & 265,8 & 136,7 \\
\hline Procura conversar com você & 264,9 & 132,1 \\
\hline Solicita que você faça algo por ele & 245,5 & 137,8 \\
\hline Conta às coisas boas ou ruins ocorridas com ele em relação ao trabalho & 221,2 & 150,6 \\
\hline Expressa desejos e preferências, dando razão para suas ações e posições & 182,4 & 150,5 \\
\hline Pede para que você o ajude em alguma atividade & 171,7 & 128,0 \\
\hline Conta às coisas boas ou ruins ocorridas com ele em relacão aos amigos & 158,3 & 174,0 \\
\hline
\end{tabular}

Nota: A frequiência foi apontada usando una escala que variou de 0: nunca; 1: uma vez por ano; 12: uma vez por mês; 52: uma vez por semana; 104: várias vezes por semana e 365: todo dia.

Pontuação mínima para todos os itens $=0$, pontuação máxima para todos os itens $=365$.

$\mathrm{N}=58, \alpha=0,92$. 


\section{Fabiana Cia}

Para Feldman e Klein (2003) e Schneider, Atkinson e Tardif (2001), a promoção de diálogo entre pai e filho faz com que estabeleçam um relacionamento seguro, o que, por sua vez, abrirá caminhos para outras experiências sociais que o filho terá.

Segundo relatos dos pais, os filhos procuravam seu apoio quase que diariamente. Por exemplo, conversava com o pai, solicitava que ele fizesse algo, contava as coisas boas ou ruins ocorridas na escola com ele ou com os amigos. Flouri e Buchanan (2003) afirmam que crianças com melhor desempenho acadêmico tinham apoio de outros familiares (irmãos, pai), além do da mãe. Em média, a maioria dos pais relatou que usava todas as formas de comunicação com seus filhos incluídas neste estudo, quase todos os dias.

Como mostram os dados da Tabela 2, os filhos apontaram maior freqüência de comunicações do tipo "fazer perguntas referentes ao seu dia a dia" e "Ihe dar carinho". Ao comparar os dados da Tabela 1 com os da Tabela 2, nota-se que a freqüência de comunicação, segundo os pais, era muito parecida com a relatada pelos filhos, o que mostra que há coerência entre a visão de um e outro. A alta freqüência de comunicação entre pais e filhos é indicativa de que os pais desta amostra estavam sendo importantes agentes de socialização para os filhos (Schneider \& cols., 2001; Flouri \& Buchanan, 2003), o que contribui diretamente para seu desenvolvimento socioemocional e aprendizagem acadêmica (Del Prette \& Del Prette, 2001; Rajczuk, 2003).

\section{Participação dos pais nas atividades escolares, culturais e de lazer dos filhos}

As pesquisas apontam vários benefícios da participação ativa do pai nas conquistas acadêmicas do filho, demonstrando interesse e auxiliando (Vizzotto, 1988; Biller \& Kimpton, 1997; Coley, 1998; Engle \& Breaux 1998; Amato \& Gilbreth, 1999; Flouri \& Buchanan, 2003). Além disso, fornecer estímulos culturais e de lazer para os filhos também contribui para seu desenvolvimento. A Tabela 3 considera a participação dos pais nas atividades escolares, culturais e de lazer dos filhos.

Tabela 3: Escala da participação do pai nas atividades escolares, culturais e de lazer do filho

\begin{tabular}{lcc}
\hline \multicolumn{1}{c}{ Item } & $\begin{array}{c}\text { Freqüência } \\
\text { média } \\
\text { (dias/ano) }\end{array}$ & D. P. \\
\hline Atividades escolares & & \\
\hline Incentiva seu filho a ler (livros, revistas, jornais) & 304,7 & 127,2 \\
Incentiva seu filho a assumir responsabilidade por tarefas escolares & 271,4 & 143,6 \\
Valoriza as conquistas acadêmicas de seu filho & 238,0 & 151,0 \\
Incentiva seu filho a brincar com jogos educativos & 193,8 & 160,3 \\
Auxilia seu filho nas lições de casa & 169,5 & 155,1 \\
Acompanha o progresso escolar do seu filho & 162,9 & 143,7 \\
Lê/Conta histórias para seu filho & 69,7 & 111,6 \\
Mantém contato com o (s) professores (es) do filho & 24,3 & 76,2 \\
\hline Atividades culturais e de lazer & & \\
\hline Valoriza as conquistas esportivas de seu filho & 237,2 & 157,5 \\
Incentiva seu filho a ter contato com outros adultos (tios, primos) & 179,6 & 157,0 \\
Incentiva seu filho a ter contato com outras crianças & 158,5 & 161,4 \\
Brinca com seu filho & 181,8 & 154,8 \\
Assiste filme com seu filho da escolha dele & 144,9 & 161,5 \\
Passeia com seu filho (shopping, zoológico, casa de familiares etc.) & 115,2 & 140,1 \\
Assiste eventos culturais com seu filho (teatro, cinema, shows musicais) & 44,8 & 105,7 \\
\hline
\end{tabular}

Nota A frequência foi apontada usando uma escala que variou de 0: nunca; 1: uma vez por ano; 12: uma vez por mês; 52: uma vez por semana; 104: várias vezes por semana e 365: todo dia.

Pontuação mínima para todos os itens $=0$, pontuaçăo máxima para todos os itens $=365 . \mathrm{N}=58, \alpha=0,91$.

Como mostram os dados da Tabela 3, os pais participavam com maior freqüência nas atividades de "incentivar o filho a ler", "incentivar o filho a assumir responsabilidades escolares" e "valorizar as conquistas acadêmicas do filho”. A alta freqüência com a qual os pais participavam destas três atividades junto 
com o filho foi apontada por Vizzotto (1988); Huntsinger, Jose e Larson (1998); Bhering e De Nez (2002); Ferreira e Marturano (2002), e como sendo preditores da aprendizagem acadêmica, disciplina e motivação dos filhos para os estudos.

\section{Desempenho acadêmico das crianças e relacio- namento pai-filho}

A Tabela 4 mostra os escores obtidos no Teste de Desempenho Escolar das crianças da 5a e 6ª séries.

Tabela 4: Resultados obtidos no Teste de Desempenho Escolar

\begin{tabular}{lllll}
\hline & 5" série & & 6 série & \\
\hline TDE & Média & D. P. & Média & D. P. \\
\hline Aritmética & 23,2 & 2,6 & 22,2 & 4,8 \\
Escrita & 27,8 & 5,6 & 28,6 & 4,5 \\
Leitura & 68,4 & 1,5 & 68,8 & 1,4 \\
\hline Pontuação total & 119,4 & 7,5 & 119,9 & 7,5 \\
\hline
\end{tabular}

Nota: Pontuação máxima possível nos subtestes do TDE: aritmética $=38 ;$ escrita $=35 ;$ leitura $=70$

Como pode ser visto na Tabela 4, em relação ao desempenho acadêmico, as crianças da 5 a série obtiveram pontuações medianas nos subtestes de aritmética e leitura e pontuações abaixo da média no subteste de escrita. As crianças da $6^{\mathrm{a}}$ série obtiveram pontuações medianas no subteste de leitura e pontuações abaixo da média nos subtestes de aritmética e escrita, considerando as normas de classifica- ção do TDE. Nos subtestes de aritmética e leitura, foram excluídas os dados de duas crianças (uma em cada subteste), por representarem valores extremos, ou seja, escores significativamente abaixo da média obtida por outras crianças da amostra. Possivelmente isto ocorreu porque essas crianças não entenderam o propósito do teste ou por apresentarem dificuldades de aprendizagem.

Para correlacionar as medidas do relacionamento pai-filho com o desempenho acadêmico das crianças, foi necessário combinar os escores das crianças da $5^{\mathrm{a}}$ e $6^{\underline{a}}$ séries no TDE. Sempre que é preciso combinar dados de dois grupos independentes, com distribuições normais, mas médias diferentes, pode-se subtrair ou somar um valor fixo a todos os escores de um dos grupos, para transpor a média para o mesmo valor do segundo grupo, sem afetar a forma da distribuição dos escores do primeiro grupo. Sendo assim, optou-se por transformar os escores das crianças da $6^{a}$ série para ter uma distribuição equivalente à das crianças da 5a série. Para tanto, foram retirados três pontos dos escores de cada criança da $6^{\underline{a}}$ série em aritmética, dois pontos em escrita e cinco pontos da pontuação total no TDE.

A Tabela 5 apresenta as correlações entre as pontuações das crianças no TDE e as três escalas de relacionamento entre pai e filho.

Tabela 5: Correlações entre as medidas do desempenho acadêmico e do relacionamento entre pai e filho

\begin{tabular}{|c|c|c|c|c|c|c|}
\hline & \multicolumn{6}{|c|}{ Teste de Pearson $(r)$} \\
\hline & 1 & 2 & 3 & 4 & 5 & 6 \\
\hline $\begin{array}{l}\text { 1- Comunicações entre pai e } \\
\text { filho, segundo o pai }\end{array}$ & --- & & & & & \\
\hline $\begin{array}{l}\text { 2- Comunicações entre pai e filho, } \\
\text { segundo o filho }\end{array}$ & $0,589 * *$ & --- & & & & \\
\hline $\begin{array}{l}\text { 3- Participação do pai nas } \\
\text { atividades escolares, culturais e de } \\
\text { lazer do filho }\end{array}$ & $0,805^{* * *}$ & $0,311 *$ & --- & & & \\
\hline $\begin{array}{l}\text { 4- Pontuação no TDE em } \\
\text { aritmética }\end{array}$ & 0,058 & 0,091 & $-0,147$ & --- & & \\
\hline 5- Pontuação no TDE em leitura & $0,666^{* * *}$ & $0,422 * *$ & $0,491^{* * *}$ & $0,307 *$ & -.- & \\
\hline 6- Pontuação no TDE em escrita & $0,565^{* * *}$ & $0,329 *$ & $0,367^{* *}$ & $0,278^{*}$ & $0,605 * * *$ & $\ldots$ \\
\hline 7- Pontuação total no TDE & $0,450^{* *}$ & $0,337 *$ & $0,344 *$ & $0,740^{* * *}$ & $0,619 * * *$ & $0,833^{* * *}$ \\
\hline
\end{tabular}

Nota: Os itens de 1 a 3 referem-se às escalas de relacionamento entre pai e fillho e os itens de 4 a 7 à pontuação no TDE das crianças. ${ }^{*} p<0,05 ; * * p<0,01, * * * p<0,001$. 


\section{Fabiana Cia}

Como mostram os dados da Tabela 5, as três escalas que avaliaram o relacionamento entre pai e filho estão positivamente correlacionadas entre si, ou seja, quanto maior a freqüência de interação em um domínio, maior a freqüência nos outros domínios. Outras pesquisas que levantaram informações acerca de vários aspectos do relacionamento entre pai e filho também evidenciaram que a alta participação do pai se dava em todos os aspectos e não apenas em um isolado (Flouri \& Buchanan, 2003).

Esses dados indicam que está aparecendo um novo padrão de paternidade, pois os pais não estão somente oferecendo suporte financeiro, mas participando, junto com a esposa, na educação dos filhos. Essa "nova paternidade” também foi verificada em outras pesquisas envolvendo a figura paterna (Lamb, 1997; Dessen \& Lewis, 1998; Jablonski, 1999; Bertolini, 2002; Costa, 2002; Hennigen \& Guareschi, 2002).

O que pode estar contribuindo para essa alta participação dos pais na educação dos filhos é o aumento crescente do ingresso da mulher no mercado de trabalho. O que contribuiu para a estabilidade econômica da família e alterou as relações de poder entre homens e mulheres, havendo uma transformação nos papéis sociais ligados ao gênero no que diz respeito à participação em trabalho fora e dentro de casa (Brandth \& Kvande, 2002). Sendo assim, a mulher passou a esperar outros tipos de resultados em suas interações no grupo familiar (Rodrigues, Assmar \& Jablonski, 2002) e deixou de assumir toda a responsabilidade em relação aos filhos, favorecendo um envolvimento paterno direto. No geral, esta nova divisão de tarefas resulta em uma melhoria nas relações familiares, uma vez que ambos os membros do casal entendem a importância das demandas profissionais e familiares e as crianças se beneficiam do maior envolvimento dos pais (Bertolini, 2002).

Pode-se verificar que as escalas que avaliavam o relacionamento entre pai e filho estavam positivamente correlacionadas com o desempenho acadêmico das crianças em escrita, leitura e com a pontuação total no TDE, ou seja, quanto maior a freqüência de comunicação entre pai e filho e da participação do pai nas atividades escolares, culturais e de lazer do filho, maior a pontuação das crianças em escrita e leitura e maior o desempenho acadêmico das crianças.

Assim, quanto mais freqüente as interações entre os pais e seus filhos, melhor o desempenho acadêmi- co das crianças, corroborando com pesquisas realizadas em outros contextos culturais, que também demonstraram a importância da qualidade do relacionamento entre pai e filho para o desempenho acadêmico das crianças (Vizzotto, 1988; Biller \& Kimpton, 1997; Coley, 1998; Amato \& Gilbreth, 1999; Bacete \& Betoret, 2000; Flouri \& Buchanan, 2003; Pelegrina \& cols., 2003).

É interessante notar que, a maioria dos aspectos relacionados diretamente à participação do pai na educação do filho, que foram investigados neste estudo, se referia ao contexto interno da família e não ao contexto escolar. Sendo assim, pode-se afirmar, a partir das correlações estabelecidas entre o desempenho acadêmico e a qualidade do relacionamento entre pai e filho, que o sucesso acadêmico da criança, pelo menos em parte, está relacionado ao seu contexto familiar.

No entanto, apesar da alta freqüência do envolvimento do pai, nota-se que o desempenho acadêmico da maioria das crianças não estava elevado, sendo que muitas crianças tiveram pontuações abaixo da média. Estes dados vêm confirmar que há outras variáveis envolvidas no desempenho acadêmico, como contexto social e cultural da criança, características individuais e qualidade do ensino (Coley, Morris \& Hernandes, 2004; Marturano, 2004).

Diante disso, além da escola se atentar para o maior envolvimento dos pais nas atividades escolares dos filhos, também deveria garantir intervenções com as crianças com baixo desempenho acadêmico no âmbito escolar, bem como, proporcionar aos professores cursos de formação continuada para aprimorar a didática dos mesmos.

\section{Considerações Finais}

Apesar de este estudo ter sido realizado em apenas uma escola e com uma população com aspectos socioeconômicos restritos, a presente pesquisa contribuiu para o melhor entendimento da influência que o envolvimento do pai com o filho tem sobre o desempenho acadêmico do filho, à medida que se obtiveram informações relevantes sobre os principais aspectos do relacionamento entre pai e filho e sobre o desempenho acadêmico do filho. Outra contribuição desta pesquisa foi quanto à elaboração e aplicação de um instrumento de coleta de dados direcionado à figura paterna. Na literatura brasileira, há uma carência de 
instrumentos que possam trazer informações para o entendimento do relacionamento entre pai e filho. Desta forma, este instrumento pode ser utilizado em outros estudos de levantamento e de pesquisa-intervenção.

Tais resultados podem trazer subsídios para embasar a elaboração de intervenções com pais que trabalham, para criar estratégias e conciliar as demandas do trabalho com as da família. Percebe-se a importância de intervenções com os pais cujos filhos estão ingressando na escola, para que estes se conscientizem da sua importância para o bom desempenho acadêmico do filho, explicando algumas estratégias para maximizar o desempenho acadêmico do mesmo. Vários pesquisadores afirmaram que existem benefícios para o pai, a mãe e o filho quando o pai participa de intervenções que trabalham aspectos do relacionamento entre pai e filho (Fagan \& Iglesias, 1999; Gavin \& cols., 2002).

\section{Referências Bibliográficas}

Amato, P.R. \& Gilbreth, J.G. (1999). Nonresident fathers and children's well-being: A meta-analysis. Journal of Marriage and the Family, 61, 557-573.

Bacete, F. J.G. \& Betoret, F.D. (2000). Motivación, aprendizaje y rendimiente escolar. Revista Española de Motivación y Emoción, 1, 55-65.

Bertolini, L. B. A. (2002). Funções paternas, maternas e conjugais na sociedade ocidental. Em A.L.B. Bertolini (Org.), Relações entre o trabalho da mulher e a dinâmica familiar (pp. 27-31). São Paulo: Vetor.

Bhering, E. \& De Nez, T. B. (2002). Envolvimento de pais em creche: Possibilidades e dificuldades de parceria. Psicologia: Teoria e Pesquisa, 18, 63-73.

Biller, H. B. \& Kimpton, J. L. (1997). The father and school-age child. Em M. E. Lamb (Org.), The role of the father in child development (pp. 1-18). New York: John Wiley \& Sons.

Black, M. M., Dubowitz, H. \& Starr, R.H. (1999). African American fathers in low income, urban families: Development, behavior, and home environment of their three-year-old children. Child Development, 70, 967-978.

Bolsoni-Silva, A.T. (2000). Problemas de com- portamento e comportamentos socialmente adequados: Sua relação com as atividades educativas de pais. Dissertação de Mestrado, São Carlos: UFSCar.

Brandth, B. \& Kvande, E. (2002). Reflexive fathers: Negotiating parental leave and working life. Gender, Work and Organization, 9, 186-203.

Cohen, S. \& Williamson, G. M. (1988). Perceived stress in a probality sample of Unites States. Em S. Spacapan \& S. Oskamp (Ogrs.), The social psychology of health (pp. 34-39).Neiwburg Park, CA.. Sage.

Coley, R.L. (1998). Children's socialization experiences and functioning in single-mother households: The importance of fathers and other men. Child Development, 9, 219-230.

Coley, R.L., Morris, J. E. \& Hernandez, Z.D. (2004). Out-of-school care and problem behavior trajectories among low-income adolescents: Individual, family, and neighborhood characteristics as added risks. Child Development, 73, 948-965.

Costa, R.G. (2002). Reprodução e gênero: Paternidades, masculinidades e teorias da concepção. Revista Estudos Feministas, 10, 339-356.

Del Prette, A. \& Del Prette, Z. A. P. (2001). Psicologia das relações interpessoais:Vivências para o trabalho em grupo. Petrópolis: Vozes.

Dessen, M. A. \& Lewis, C. (1998). Como estudar a família e o pai. Paidéia: Cadernos de Psicologia e Educação 14-15, 105-119.

Diniz, G. (1999). Homens e mulheres frente à interação casamento trabalho: Aspectos da realidade brasileira. Em T. Féres-Carneiro (Org.), Casal e família: Entre a tradição e a transformação (pp. 31-54). Rio de Janeiro: NAU.

Engle, P.L. \& Breaux, C. (1998). Fathers' involvement with children: Perspectives from developing countries. Social Policy Report: Society for Research in Child Development, 12, 1-23.

Fagan, J. \& Iglesias, A. (1999). Father involvement program effects on fathers, father figures, and their head start children: A quasi-experimental study. Early Childhood Research Quarterly, 14, 243-269. 


\section{Fabiana Cia}

Faria, G. S. \& Barham, E. J. (2002). Práticas de emprego e o equilíbrio trabalho-família. Monografia de conclusão de Bacharelado em Psicologia, Universidade Federal de São Carlos, São Carlos, São Paulo.

Feldman, R. \& Klein, P. S. (2003). Toddlers' self-regulated compliance to mothers, caregivers, and fathers: Implications for theories of socialization. Developmental Psychology, 39, 680-692.

Ferreira, M. C. T. \& Marturano, E. M. (2002). Ambiente familiar e os problemas do comportamento apresentados por crianças com baixo desempenho escolar. Psicologia: Reflexão e Crítica, 15, 35-44.

Flouri, E. \& Buchanan, A. (2003). The role of father involvement in children's later mental health. Journal of Adolescence, 26, 63-78.

Gavin, L. E., Black, M.M., Minor, S., Abel, Y., Papas, M.A. \& Bentley, M.E. (2002). Young, disadvantaged fathers' involvement with their infants: An ecological perspective. Journal of Adolescent Health, 31, 226-276.

Hennigen, I. \& Guareschi, N. M. F. (2002). A paternidade na contemporaneidade: Um estudo de mídia sob a perspectiva dos estudos culturais. Psicologia e Sociedade, 14, 44-68.

Huntsinger, C. S., Jose, P. E. \& Larson, S. L. (1998). Do parent practices to encourage academic competence influence social adjustment of young European American and Chinese American children? Developmental Psychology, 34, 747-756.

Jablonski, B. (1999). Identidade masculina e o exercício da paternidade: De onde viemos e para onde vamos. Em T. Féres-Carneiro (Org.), Casal e família: Entre a tradição e a transformação (pp. 5569). Rio de Janeiro: NAU.

Lamb, M. E. (1997). Fathers and child development: An introductory overview and guide. Em M. E. Lamb (Org.), The role of the father in child development (pp. 1-18). New York: John Wiley \& Sons.

Lewis, C. \& Dessen, M. A. (1999). O pai no contexto familiar. Psicologia: Teoria e Pesquisa, 15, 9-16.

Marshall, D. B., English, D. J. \& Stewart, A. J. (2001). The effect of fathers or father figures on child behavioral problems in families referred to child protective services. Child Maltreatment, 6, 290-299.

Marturano, E. M. (2004). Fatores de risco e proteção no desenvolvimento sócio-emocional de crianças com dificuldade de aprendizagem. Em E. G. Mendes, M. A. Almeida \& L. C. A. Williams (Orgs.), Temas em Educação Especial - Avanços Recentes (pp. 159-165). São Carlos: EDUFSCar.

Mendes, E. G. (2002). Construindo a escola inclusiva. Em M. Palhares \& S. Martins (Orgs.), A escola inclusiva (pp. 1-15). São Carlos: EDUFSCar.

Pelegrina, S., García-Linares, M. C. \& Casanova, P. F. (2003). Adolescents and their parents' perceptions about parenting characteristics. Who can better predict the adolescent's academic competence? Journal of Adolescence, 26, 651-665.

Rajczuk, L. (2003). A sociabilidade de crianças como fator de proteção. Dissertação de Mestrado, Ribeirão Preto: FMRP USP.

Rodrigues, A., Assmar, E. M. L. \& Jablonski, B. (2002). Psicologia Social. Petrópolis: Editora Vozes.

Schneider, B. H., Atkinson, L. \& Tardif, C. (2001). Child - parent attachment and children's peer relations: A quantitative review. Developmental Psychology, 37, 86-100.

Sorano, A. C. \& Barham, E. J. (1999). Diferenças entre os membros do casal devido ao gênero em relação ao trabalho doméstico. Monografia de conclusão de Bacharelado em Psicologia, São Carlos: UFSCar.

Stein, L. M. (1994). Teste de desempenho escolar. São Paulo: Casa do Psicólogo.

Vallejo-Nágera, J. A. (1997). Guía práctica de psicología. Madrid: Temas de Hoy.

Vizzotto, M. M. (1988). Ausência paterna e rendimento escolar. Dissertação de Mestrado, Campinas: PUCCAMP.

Trabalho derivado de Dissertação de Mestrado, parte dos resultados antecipadamente apresentado em evento científico. 